\title{
Ensuring Human Rights for the Gender Diverse Population in Bangladesh: The Protection Perspectives
}

\author{
Humaira Anjum*, Rifa Tamanna, Subrina Reza, Suraiya Kamol, Tanzum Abid Khan \\ Bandhu Social Welfare Society, School of Law, BRAC University, Dhaka, Bangladesh \\ Email: `humaira.oishe@gmail.com, 11rifatamanna@gmail.com, subrina.sara.reza@gmail.com, \\ tanzum.abid@gmail.com,suraiya.kamoll@gmail.com
}

How to cite this paper: Anjum, H., Tamanna, R., Reza, S., Kamol, S., \& Khan, T. A. (2021). Ensuring Human Rights for the Gender Diverse Population in Bangladesh: The Protection Perspectives. Beijing Law Review, 12, 342-378.

https://doi.org/10.4236/blr.2021.122020

Received: October 27, 2020

Accepted: April 13, 2021

Published: April 16, 2021

Copyright $\odot 2021$ by author(s) and Scientific Research Publishing Inc. This work is licensed under the Creative Commons Attribution International License (CC BY 4.0).

http://creativecommons.org/licenses/by/4.0/

\begin{abstract}
The existence of the gender diverse population in Bangladesh is overcast. Officially, the state has already denied the existence of people from different gender identities other than male, female and third gender, the rearmost of which is not even properly defined. This study aims to clearly define gender terminologies that should be included in addition to the "Third Gender" purview recently acknowledged in the context of Bangladesh and to identify the existent barriers and social reaction of including such definition in the legal regime. In this context, gender diverse population refers to the extent to which a person's gender identity, role, or expression differs from the conventional gender identity of male and female. To test the hypothesis that, there exist people of different gender identity in Bangladesh and separate legislation can be formed for coining the terminologies of different gender identities, primary research was concluded through analysis of scholarly articles, books, and other sources relevant to our field of research as literature review, and an online survey was distributed among the general population through random sampling. Furthermore, in-depth and door to door interviews were conducted and the data is compiled through narrative analysis. The results show various dimensions of outlook from people of different backgrounds and separate legislation for coining the terminologies of different gender identities is long down the road. The result suggests that sensibility of tolerance towards the gender diverse population is growing among the younger generation who are more likely to invest in ensuring equal rights for everyone; however, the same sensibility is not reflected among the rest of the society. The initial step could be to give the gender diverse population a proper recognition that is to concede their existence in the constitution and in relevant laws.
\end{abstract}




\section{Keywords}

Gender Diverse Population, Bangladesh, Definition, Human Rights

\section{Introduction}

The Constitution of the People's Republic of Bangladesh pledges to ensure nondiscrimination regardless of religion, race, caste, sex or place of birth. Being a Muslim majority state and while having provision in the Penal Code, 1860 which is known as "sodomy law", Bangladesh has made progress in recognizing the "Transgender" community which might reflect the pledged nondiscrimination that is underway. However, the country still sanctions carnal intercourse which according to the law, is against the order of nature with any man, woman or animal and the punishment for this includes imprisonment for life, or with imprisonment of either description for a term which may extend to ten years or with a death penalty and liable to be fined. It is not just about whether the legal status is ensured, which clearly would compel the people to reconsider their mindset towards the LGBTQ+ community. It is also the societal attitude towards accepting people of diverse gender identities. It is very important to under the concept of sex and gender, sound similar but actually defined in a different manner. While sex refers to biological attributes, gender refers roles, behaviors, expressions and identities constructed by society. Hence, it is both related to the State's capacity to protect and the attitude of the public and their tolerance. One has to identify the reason behind a negative attitude and it can be seen that the reason is not always religious. Almost no cases are brought to court with respect to the provision against the LGBTQ+ community, but there are numerous numbers of incidents of harassment, humiliation, murder, rape and grievous offences against the said community. The social pressure to push into what is considered natural and normal which brings the psychological implications is also terrifying since most people have little to no knowledge on the concept of gender identities.

Therefore, defining gender identities could be the steppingstone on the oath to ensuring their legal status. Not only defining the terminologies will help people understand the concepts properly in building tolerance and acceptance, the legal representation in terms of right to property, inheritance, health, personal liberty and dignity will be ensured.

\section{Literature Review}

Baudh (2013), on the matter of decriminalization of consensual same-sex sexual acts in the South Asian countries has talked about legal provisions and punishments that subsists against same sex sexual acts in countries like Bangladesh, India, Maldives, Pakistan and Sri Lanka. The author of the book has reviewed the social and legal context of these countries and how the said countries deal with the existence of the community having diverse identity. On the basis of a news- 
paper article, the author has pointed out that law enforcement agencies in Bangladesh use Section 377 of the Penal Code 1860 to harass the MSM (men who have sex with men). However, the book also found contradictory opinions as to the non-application of such law against LGBTQ community. The book included the work of another researcher Sikder and pointed that "Joya" a person who self-identifies as Hijra, shared her personal experiences of arrest, custodial violence and abuse in Bangladesh. The author also highlighted on Section 54 of the Criminal Procedure Code in Bangladesh and Section 86 of the DMP Ordinance stating that these laws also are used as an instrument of violation against anyone, not just hijras or transgender persons. The Court recommended revision of section 54 after Bangladesh Legal Aid and Services Trust (BLAST) challenged the said section 54 in the Supreme Court of Bangladesh High Court Division in 1998 in BLAST and others v. Bangladesh and others in 2003.. In terms of social, family and religious context it was found that in Bangladesh, the only recognition of LGBTQ people is the existence of the small but visible hijra community. Consequently, the majority of Bangladeshis associate homosexuality with hijras. Very few people have come out in Bangladesh and the reaction to their coming out has been mixed. Some other people who have come out have been ostracized by their families and many have been driven to marrying the opposite sex through the general societal and familial approbation. Once married, they are rehabilitated, even though most married gay men continue to have clandestine sexual liaisons with other men/boys. Baudh explained the work done by a researcher Ishtiaq in 2011 that since the major barrier is societal, not legal, the process to tackle it would be to address the issues socially. According to $\mathrm{Ru}$ thann Robson (2017), it is important to integrate the concepts of LGBTQ community and education while the researcher explored the role of LGBTQ law professors in empowering students. He has stated that when it comes to sexualities and gender identities, there are neither clear category of novice/expert, nor should there be. Moreover, there is rarely a commonality of experience, even when a seemingly definitional label such as "lesbian" might be accurately applied. He emphasized that even though there are no experts on the terminologies, it must be carefully applied and so it is important that people are being educated on such matter.

In the paper of Wojcik (2016), the countries that have accepted and included different terms of gender identities and sexual orientation in their national legislations and constitutions include Bolivia, Ecuador, Fiji, Kosovo, Malta, Mexico, Portugal, South Africa, and Sweden. Sexual orientation is also protected under the Human Rights Act of New Zealand and "Gender identity" is protected as an additional category under the constitutions of Bolivia, Ecuador, and Malta. The Constitution of Fiji protects not only sexual orientation and gender identity, but also "gender expression". Amundsen (2018) emphasized on social situations rather than legal mechanisms on the subject of acceptance of the diverse identity community. He mentioned that their critical situation is exacerbated by a strong, pre-existing social stigma against homosexuality in Bangladesh. Moreover, it is 
stated that even though same-sex sexual activity is illegal under the Bangladeshi criminal code, the law is not systematically applied and no cases have led to legal proceedings or convictions. However, the problem lies in significant harassment, public exposure and stigmatization of homosexuals by the society. This has also compelled the non-governmental organizations in Bangladesh that advocate for LGBTQ rights to take a low profile.

Hossain (2019) talked about a historic move taking place in February 2009, the first report on gender and sexual minorities of Bangladesh was submitted to the United Nations Office of the High Commissioner on Human Rights' Universal Periodic Review. The submission of the report was a historic move because it was the first time that the issue of gender and sexuality in Bangladesh was flagged at any high-level international symposium. However, the government of Bangladesh categorically rejected the recommendation in the report to decriminalize consensual same-sex sexuality by repealing section 377 . Furthermore, the foreign minister of Bangladesh denied the existence of homosexuality during the discussion of the report.

\section{Gender Terminologies (Definitions of Different Gender Identities)}

Since the path to recognition requires determination of defined genders, on the basis of primary (interviews and surveys) and secondary resources this research paper has identified the possible gender terminologies and definitions thereof which can be implemented in granting legal status to gender diverse community. The given terms can be integrated in legal provisions as to clarify what constitutes various gender identities.

\subsection{Existing Gender Terminologies}

In order to legally recognize people of different gender identities, it is necessary to be familiarized with the components that construct different gender identities. Understanding the specific terminologies of all gender identities will clarify confusions and will make it easier to realize that the denial of the existence of an entire community should not be encouraged and accepted. For instance, years ago, people from the entire Asia were categorized under the term "Mongoloid" which does not nearly represent the entire Asia but only a small portion of it. Diversity exists and there are various sexual orientations defining the diverse identities will give us a proper understanding of how significant it is to recognize this community. The part is written by collecting relevant information from primary and secondary materials and resources. The method followed for this part is doctrinal and desk-based since all terminologies are not collected by primary investigation or interview. Hence, the terminologies are not conclusive or inviolable.

\subsection{Interview and Survey Findings on Terminologies}

From the in-depth interviews, the researchers were able to define the gender 
Table 1. Existing definitions of gender-diverse population.

\begin{tabular}{|c|c|c|}
\hline Letter/Word & Terminology & Definition \\
\hline \multirow[t]{2}{*}{ A } & $\begin{array}{l}\text { Androgyny/ } \\
\text { Androgynous }\end{array}$ & $\begin{array}{l}\text { - A gender expression that has elements of both masculinity and femininity; occasionally used in place of } \\
\text { "intersex" to describe a person with both female and male anatomy. }\end{array}$ \\
\hline & Asexual & $\begin{array}{l}\text { - A person who experiences little or no sexual attraction to others and/or a lack of interest in sexual } \\
\text { relationships/behavior. They may or may not experience emotional, physical, or romantic attraction. } \\
\text { - Having a lack of (or low level of) sexual attraction to others and/or a lack of interest or desire for sex or } \\
\text { sexual partners. Asexuality exists on a spectrum from people who experience no sexual attraction or have } \\
\text { any desire for sex to those who experience low levels and only after significant amounts of time, many of } \\
\text { these different places on the spectrum have their own identity labels. Another term used within the asexual } \\
\text { community is "ace," meaning someone who is asexual. }\end{array}$ \\
\hline
\end{tabular}

Bisexual

Bi-gender

$\mathrm{D}$

Gay

Gender-fluid

$\mathrm{L}$

M

Q

Queer

Questioning

$\mathrm{T}$

Transgender ${ }^{\star}$

Trans-man/

Trans-woman
- A person who experiences attraction to some men and women.

- A person who fluctuates between traditionally "woman" and "man" gender-based behavior and identities, identifying with two genders (or sometimes identifying with either man or woman, as well as a third, different gender).

- Someone who doesn't develop sexual attraction to anyone until they have a strong emotional connection.

- Referring to a masculine presenting lesbian. While often used derogatorily, it is also reclaimed affirmatively by some lesbians and gay women as a positive self-identity term.

- A term used to describe individuals who are primarily emotionally, physically, and/or sexually attracted to members of the same sex and/or gender. More commonly used when referring to males/men-identified people who are attracted to males/men-identified people, but can be applied to females/women-identified people as well.

- Experiences attraction solely (or primarily) to some members of the same gender. Can be used to refer to men who are attracted to other men and women who are attracted to women.

- According to the Oxford English Dictionary, a person who does not identify with a single fixed gender; of or relating to a person having or expressing a fluid or unfixed gender identity.

- An umbrella term used to describe a wide range of natural bodily variations. In some cases, these traits are visible at birth, and in others, they are not apparent until puberty. Some chromosomal variations of this type may not be physically apparent at all.

- Term for a combination of chromosomes, gonads, hormones, internal sex organs, and genitals that differs from the two expected patterns of male or female.

- Women who are primarily attracted romantically, erotically, and/or emotionally to other women.

- Initials for "men who have sex with men" and "women who have sex with women," to distinguish sexual behaviors from sexual identities. Often used in the field of HIV/Aids education, prevention, and treatment.

- People who identify as queer embrace identities and sexual orientations outside of mainstream heterosexual and gender norms. A term people often use to express fluid identities and orientations.

- An individual who or time when someone is unsure about or exploring their own sexual orientation or gender identity.

- An identity label used to describe a person whose gender identity does not align with the socially expected one according to their sex assigned at birth.

- Third Gender.

- A person who has transitioned their identity from woman to man, and sometimes their body from female to male/A person who has transitioned their identity from man to woman, and sometimes their body from male to female.

Others

LGBTQI+, GSM, DSG, TGNC
- Shorthand or umbrella terms for all folks who have a non-normative (or queer) gender or sexuality, there are many different initials people prefer. LGBTQ is Lesbian Gay Bisexual Transgender and Queer and/or Questioning and Intersex (sometimes people at $\mathrm{a}+$ at the end in an effort to be more inclusive), GSM is Gender and Sexual Minorities, DSG is Diverse Sexualities and Genders, TGNC is Transgender and Gender Non-Conforming.

*In Bangladesh-along with male, female and others-third gender has been recognized as separate gender in Bangladesh. However, there is no clear and legal definition of the term "transgender" or "third gender" given by any official document. 
Table 2. Definitions extracted from surveys and interviews.

\begin{tabular}{lll}
\hline Letter Terminology & Definition \\
\hline A & $\begin{array}{l}\text { Androgynous } \\
\text { Woman }\end{array}$ & A biological woman with a combination of masculine and feminine characteristics into an ambiguous form. \\
B & Bi-sexual Man & A biological man with a romantic attraction toward both males and females, or to more than one sex or gender. \\
& Bi-sexual Woman & A biological woman with a romantic attraction toward both males and females, or to more than one sex or gender. \\
G & Gay & A biological man with a romantic attraction towards man and carries homosexual traits. \\
I & Inter-sex & $\begin{array}{l}\text { Individuals who are not biologically male or female but are born with any of several variations in sex characteristics } \\
\text { including chromosomes, gonads, sex hormones or genitals that do not fit the typical definitions for male or female } \\
\text { bodies. }\end{array}$ \\
L & Lesbian & $\begin{array}{l}\text { A biological woman with a romantic attraction towards the woman and carries homosexual traits. } \\
\text { Individuals whose gender identity or gender expressions differ from their sex assigned at birth and may desire medical }\end{array}$ \\
T & Transgender &
\end{tabular}

terminologies for certain groups of primary stakeholders to clear confusions regarding the definition of people from different identities existing in Bangladesh which is enunciated in Table 2 and Table 1 sheds light on the existent terminologies extracted from literature.

\section{Absence of Legal Status of Gender Diverse Population in Bangladesh: From Religious Contexts, Historical and Social Contexts, and Legal Contexts}

These three factors are very crucial in understanding why there is an absence of legal representation and recognition in the Bangladeshi society. All these factors are co-related in establishing and suggesting possible reforms and acknowledgment.

\subsection{Religious Contexts}

Religion and the LGBTQ community do not really go together and are regarded as the polar opposites. Almost every religion is against it and considers it as a sin. In around 75 countries worldwide, same-sex relations are unlawful (Ahmed, 2018). Among them the Islamic states are the predominantly against it because Islam strictly forbids homosexuality. Bangladesh regardless of not being an Islamic state, is as a Muslim majority state, strongly advocates this. According to, Surah An-Naml, Ayat 27:55, of the Quran. "Do you indeed approach men with desire instead of women? Rather, you are a people behaving ignorantly. "This particular Ayat was revealed during the time of Prophet Loot (A), when he visited the Sodom City (Sadum) on the west side of the Dead Sea. This city was drowning with high crimes, where people used to rob and kill any passerby. Moreover, they were involved in same-sex physical relationships which was later coined as sodomy (after Sodom City), and people were not ashamed to practice it openly. At first the people of Sodom were warned but they were not adhering to the preaching and according to Surah Al-Qamar, Ayat 54:33 of the Quran, 
"The people of Lot denied the warning." Consequently, the town of Sodom was to perish and the town was rained by a storm of bricks. All and everything, including Loot's wife, was destroyed. This is a very significant story in Islam and gives the incentive to the Muslim to label homosexual relationships as sin or a deviant activity; which is why majority countries despise the practice of homosexuality and deny their rights regarding inheritance and so on (Chatterjee, 2014).

A very prominent Muslim scholar of the $21^{\text {st }}$ century name Mufti Menk has mentioned in his speeches affirming that Islam does not allow homosexuality at all, just like it does not allow adultery, theft, murder and so on. He also mentions that just because we do not agree with the LGBTQ+ community, that does not give us the right to kill them or harm them. He further stated that Muslims can only invite them to the correct path, but if they are not inclined, then the Muslims can only disagree about but nothing further, because the LGBTQ+ people are human too, and harming them without any reason is against Islam. However, Islam does recognize the "Third Gender" also known as hermaphrodite. This is a biological condition which is not considered a sin and some of the records of the renowned Al-Razei doctor can be seen mentioning the hermaphrodite term and its human condition (Massad, 2002). Other than Islam, Christianity is also a religion where homosexuality is not supported. According to Biblical interpretations of the New Testament, Marriage is only for a man and woman to solemnize their love. Homosexuality and fornication is not included in these interpretations, making it not allowed and can also be considered as a sin. Homosexuality is rejected as being "unjust" in some letters of St. Paul in the Bible, and claims that men who practice gay sex will not inherit the Kingdom of God. For men and women to unite, is what the natural order depicted. In Leviticus 20:13 it is said that, "If a man lies with a male as with a woman, both of them have committed an abomination; they shall surely be put to death".

Therefore, it is quite explicit that homosexuality is not allowed and strictly prohibited. However, the Christian community believes that being humans, we are bound to sin and that God loves each and every one of His creations. That means even if anyone commits these sins, they still do not fall from God's grace. Also, the third gender views in the Christian community is quite complex, because they neither oppose it nor fully accept it. "Although a small fraction of the people experience the third gender life, the Scriptures prove that people are created in the form of God as males and females, and that sexes are compatible, giving new life differently and, curiously, representing who God is", according to Gen. 1:27. However, they do believe that God has created everyone a certain way and that everyone is loved. According to Psalm 139, "Irrespective of what disorder or anxiety any one of us may have, we are all made wonderful and fantastic" and that everyone is loved by God.

The Hindu religion on the other hand has a very diverse connection with the LGBTQ+ community. In the Hindu faith, they do not particularly have a heterosexual or homosexual distinction in their religious scriptures, but they do be- 
lieve that the act of intercourse is primarily for procreation purposes, which is possible only through the union of a male and female. Many Hindus think one of the four key objectives of life and sexual activity is a marital obligation. Hinduism believes that it is only natural for men and women to marry, and to have children. Those who reject this natural connection betray their own dharma. However, traces of homosexuality can be found in the carvings on the walls of ancient temples and also in Kama Sutra. But Kama Sutra on the other hand is not a religion scripture, therefore it cannot be held in high esteem. It was observed from our interview that most Hindu society prefers a heterosexual relationship and to them marriage is a very sacred union between a man and woman to further their lineage and for men to fulfill their "Pitri-rin" of producing a son. Therefore, according to the Hindu communities same-sex marriage is not acceptable. LGBTQ people continued to be unwelcomed in some Hindu societies, mostly representing attitudes brought from invading nations like the British Empire in India (HRC, 2004). This religion is also very tolerant of the third gender community, because many of their Hindu deities were of the same community too. One of them is their supreme God Shiva and his wife Parvati, when they literally joined their bodies together to attain the optimum ecstasy (Ogles, 2016). This depicts as being both male and female at the same time, thus referring to the third gender. Therefore, from the religious point of view, the third gender community is supposed to be respected a lot in the Hindu community.

\subsection{Historical and Social Contexts}

To properly comprehend the social perspective, we need to trace back a little bit of history too. Homosexuality or heterosexuality can't be adequately defined in Arab culture, because they do not have these words in their vocabulary to be exact. In comparison, Interco ship of the same gender does not result in anyone being gay or homosexual, there has to be a special connection or friendship, and there were several gay rulers in the Middle East during the Colonial time of Britain. Hijras or "Third Gender Population" In the royal courts of the Islamic world, played a renowned role, in particular in the Ottoman Empires and the Medieval Indian rule of Mughal. Their positions were well-known as diplomatic advisers, executive officials, generals and harem guards. The hijras were known as intelligent, optimistic, and highly faithful and had free access to any room and population and thus played a crucial role in empire building politics during the Mughal period. In this subcontinent, along with Mughal, different Zamindars under colonial rule used to employ "ghetu" groups both the musical diversion they might provide and the "ghetu" sexual services from the boys of that group. The boys from these groups would dress-up as girls and would sing and dance and would also perform sexual services for Zamindars (Bangkok Post Public Company Limited, 2012). However, these actions were not considered deviance because the Zamindars were powerful people having control over the then society creating their own definition of deviance. 
Now Bangladesh being a mixture of many cultures, it has built its identity through these histories. The culture and society of Bangladesh are strongly associated with religious beliefs and sensibilities. And none of the major religions support the LGBTQ+, which is why the backlash is high. As a Muslim majority country most of our members of the society are conservative towards the idea of homosexuality as it is considered a heinous sin according to Muslim ideology. Converting the thought process of this community is going to be very challenging. There are groups who strongly regard homosexuality as a deviant behavior which the reason that Bangladesh is still behind in this regard.

The majority of the population in Bangladesh consists of the people belonging in the first two groups who do not see the need to help the LGBTQ+ minority just yet, which is why any positive impact to come will be slow. Another reason for the high intolerance for the LGBTQ+ community is because it is highly backed by western propaganda or ideas. Even though trace homosexuality were found in Asia long before the western region, most Asian countries seem to have built a negative reflection toward the western culture and their interventions in Asian countries. Bangladesh is also no exception to this idea. This negative attitude may have a lot to contribute to the idea of the colonial era days, when the colonial empires had ruled over these Asian countries. And now that these Asian countries are independent, they no longer want any western intervention and when there is an intervention, they do not welcome it graciously.

One incident involved a Hindu woman and Muslim women were found secretly married in Bangladesh, and were arrested under the section 377 for the Penal Code, 1860. It is the first homosexual marriage of Bangladesh notwithstanding legislation which criminalizes the union (Reza, 2013). There is normal public endorsement of intimacy between same-sex friends and no dispute occurs, however, the predominantly Muslim majority country's religious practices have serious opposition to homosexuality. There were mixed reactions from the public people regarding this incident. Some were welcoming of the first same sex marriage and congratulated them. But the majority of the reactions were negative towards it, and even those who were in favor of the same sex marriage received a lot of backlash from the internet too. These few incidents are a clear indication that the Bangladeshi society is still not completely ready to accept this LGBTQ+ minority just yet.

The substantial challenge for redefining gender terminologies will be the backlash from the community and intolerance towards sexual minorities. However, creating tolerance towards the homosexual community may be possible through the campaigns and awareness programs, as they don't have to agree to this nuance rather, they will simply have to agree to disagree.

\subsection{Legal Context}

In present Bangladeshi society LGBTQ+ people are not recognized at all to the extent of denying their existence. They are believed to be involved in sin and 
they are not regarded as normal in broader as people with alternative sexual orientation are labeled as a sinner and a sick person. There is no state recognition of sexual minorities in our country where the government in one hand; denied the existence of LGBTQ+ community in Bangladesh in an International Forum and on the other hand citizens who are openly conforming to sexual minority community are being sanctioned, in some circumstances are even being killed. Xulhaz Mannan and his friend Mahbub Rabbi Tonoy, two LGBTQ activist were killed because of their sexual orientation and the killer has not been arrested in over two years (Labu, 2018). Moreover, the Penal Code 1860, Section 377 prohibits all Bangladeshi's from being engaged in any unnatural intercourse labeling homosexuality as a criminal offence punishable with life imprisonment or ten years imprisonment along with fine. This particular section 377 has caused a lot of commotion for the LGBTQ+ people, because sometimes the police would use this section to harass them even when there was no infringement of the law (Michael, 2018). However, other countries; even our neighboring country India is more liberal in this issue as they recently decriminalized homosexuality by repealing section 377 from their penal code. In 2013 The United States federally recognized same-sex marriages and 2015 The US Supreme Court ruled in Obergefell v. Hodges in 2015 that all states must legalize same-sex marriage (Yuhas, 2017). Although Bangladesh still criminalizes diverse sexual orientation the Constitution of Bangladesh Article 27 and 28 confers equal rights and dignity to every citizen, giving hope to the gender diverse community of equal rights and dignity in practice and not just in theory. The administration basically portrays the concept of the society in making the laws. In the context of Bangladesh as long as the society changes its mind and becomes tolerant towards the LGBTQ+ community the administration is bound to scrap the law criminalizing sexual minorities. Interview from a legal practitioner, who deals with the third gender population, gave us a lot of information on what basically happens if or when we start a conversation about the legal status of the LGBTQ+ community. The most crucial issue that came up was the inheritance rights. In Bangladesh, the inheritance rights fall under the roof of the personal laws, which is governed by one's particular religion. The three dominating religions in Bangladesh are Islam, Hinduism and Christianity, and they all have their own rules for inheritance. These inheritance laws are built up surrounding the idea of male and female, and not keeping any other identity in mind. Therefore, inheritance remedy cannot be found in these personal laws for the LGBTQ+ community, because it is not possible to change the contents and ideologies of a religion, because that will be an act of blasphemy.

\subsection{Positive Scenario}

Some positive light that can be shed is through the story of Hosne Ara Begum, who was born as a male but went under sex transformation to become a female in 1975 (Ashoka Bangladesh, n.d.). From then on she was recognized as a "she" 
and has been living in Bangladesh ever since and fighting for women's rights by joining the fellowship of Ashoka, because she has been acquainted with life as a male as well as a female. She is the first person in Bangladesh to have gotten a sex change and getting recognition, making this a positive step for those who seek a similar path. Another positive story is the life of Sadia Akhter Pinky, who is a member of the Third Gender and is the first from her community to become an Upazila Chairman of Jhenaidah (Khandokar, 2019). This election is won by the majority votes from the inhabitants of the Upazila, which means that she won the election with the majority votes. This would not have been possible if there was not a high tolerance for the Third Gender community in that area. People of that area trusts her and considers her as a part of their community by treating her like a human just like any other, which is why she was able to come forward and fight for the social problems she believes in and wants to protect and help the people of that area. From these two stories it also shows that the Bangladeshi community is quite accepting and adapting to these new changes in ideas like sex changes and having a Third Gender as their Upazila Chairman, from the traditional notions. It shows that Bangladesh is capable of positive reforms if only given a chance and proper promotion of the rights of these minority groups. Some of the positive initiations that can be taken came from our interviews with the LGBTQ+ community. One of which is by setting up a separate or segregated educational institute for the Third Gender people, so that they can pursue higher education, which they are mostly deprived of. This step may seem discriminatory; however women's education first started with segregated schools and later established into co-ed schools after Begum Rokeya protested for it, when women were not allowed to have or get an education. Therefore, gradual change is the key to adapting into a new idea or notion. The change of social dynamics is badly needed now more than ever to confer the rights ensured by the Constitution of Bangladesh to the sexual minorities of our society. There are different social welfare groups in Bangladesh working for the recognition of sexual minorities, but these social welfare groups are mostly very underground for safety reasons. After the killing of Xulhaz Mannan the founder of Bangladesh's first and only LGBT-themed magazine "Roopbaan" the situation has worsened and the social welfare groups are more concerned about their security (Tharoor, 2016). However, they still are working behind the curtains to safeguard the rights of sexual minorities.

\section{Compare and Contrast: Status of the Gender Diverse Population amongst Asian Countries}

Having the colonial legacy Asian states consider same sex intimacy is criminal offence. However; recently some states decriminalized penal provisions from their Penal codes.

\subsection{India}

In India homosexuality was never fully accepted and anti-homosexual views 
have developed in many ways and to varying degrees. Indian archives are full proof of homosexuality paintings and poetry from Mughal ( $15^{\text {th }}$ century onwards) is homoerotic. For instance, Konarak, Khajaraho, and other sites become places of pilgrimage for the diasporic Indian lesbian or gay man, there is an excess of Hindu temple carvings and iconography showing same-sex sexual behaviors (Khan, 2001). The idea about homosexuality is still taboo because context "homosexuality" and "homosexual behavior," does not have distinguished definition in South Asian context. Hijra(transgender) people are a fundamental component of Indian society and these individuals constitute a sub-minority in the emerging queer minority community in the country and are likely to be further alienated in different health issues. India is Kamasutra's land and while it has often been viewed a sexually conservative society, it has developed as a distinct cultural community on the Indian subcontinent and flourished for thousands of years, despite being largely marginalized. In the present time, the legalization of homosexuality in India ended the repression of the penal provision 377 of the Indian Penal Code, thus decriminalizing same-sex intimacy and intercourse. However, even as the law made a sexual minority community visible through legal recognition, the role of extralegal social, cultural, and religious modalities that continue to pathologies homosexuality was highlighted by incidents of moral police in the aftermath of decriminalization (Singh, 2015). Although India decriminalized penal provision from of its penal code after a long struggle of more than 20 years, by virtue of collective efforts of lawmakers, lawyers, media personnel, conscious and progressive citizens, however the social acceptance is not obtained. However, in Bangladesh, section 377 is still existent and has not been yet repealed or amended, thus the LGBTQ people do not have any legal recognition and acceptance in society.

\subsection{Pakistan}

In Pakistan, gender is regulated in order to affirm a traditional patriarchal structure that clearly demarcates the male and female spheres. In the judicial framework or in the social sphere, this majority Muslim culture, which possesses distinctly binary male and female roles, does not give any other gender any space. Transgender divide themselves in self-sustaining, close-knitted communities in Pakistani society, also known as Hijra or Khusra, where a leader or guru adopts transgender infants after their guardians have refused or disinherited them at a young age because of their related negative stigma and personal humiliation. In Pakistan, laws against "obscene acts" and "unnatural crimes" lead to general resentment against LGB citizens. Locally known as Khawaja Sara, transgender people are seen in a more complicated manner both as bearers of good fortune, and as outcasts their civil rights are far more respected. Therefore, their civil rights are far more secure. The Transgender Person (Protection of Rights) Act of 2018 allows anyone whose gender does not conform to the sex assigned at birth to change their legal gender on official documents, hold public 
office, and vote. The act further ensures protection from accommodation, jobs, and school discrimination. Despite these legal guarantees, social segregation, abuse and stigmatization of Khawaja Saras, transgendered, intersex and gender nonconforming Pakistanis remain a concern. In comparison, under the country's penal code, same-sex marriages are also forbidden. The death penalty may be enforced in areas of Sharia law, and public sentiment about Gay and lesbian citizens is risk. Pakistan remains a conservative country that supports traditional family roles and socially conservative beliefs. Politicians and prominent religious figures also speak out in public, as "un-Islamic" and "immoral" (Out Right Action International, 2020). Though rarely invoked, Section 377 of the Pakistan Penal Code, an injunction inherited from the British colonizers, criminalizes sodomy as an unnatural offense. With this colonial law intact, the Pakistani Supreme Court made a series of historic rulings from 2009 to 2012 in which third-sex/-gender citizens were serving a range of legal privileges and protections (Khan, 2019). The Transgender Persons (Protection of Rights) Act allows individuals select their gender on official documents, including national IDs, passports and driver's licenses, and to have that identification recognized. The bill forbids discrimination in schools, at work, on public transportation methods and when seeking medical treatment, and the legislation also specifies that the right to vote or run for office should not be stripped of transgender people (International Commission of Jurists, 2020). The Transgender Persons (Protection of Rights) Act, 2018 only acknowledges transgender people not all gender diverse people in Pakistan. Being a Muslim country like Bangladesh, Pakistan show very progressive step to ensure the right of transgender people.

\subsection{Sri Lanka}

In Sri Lanka there are strongly rooted assumptions on the way men and women can look and behave. Many that criticize gender rules including many lesbian, homosexual, bisexual, transgender and intersex (LGBTQI+) people will face a number of violations by state individuals and local citizens that threaten the health and protection of their everyday lives, to their realizing basic human rights (Human Rights Watch, 2016). For many decades, Sri Lanka has been discussing the decriminalization of homosexuality, but never more intensely than in 2017, when the government proposed this constitutional reform. This initiative was ultimately scrapped; prompting strong resistance from local non-governmental "LGBT" organizations (NGOs), start work in the country. The site of conflict between the state and civil society is rife with the problematics of nation and capital, for the NGO reifies ethno-nationalism and capitalist social cleavages. NGOs demarcate an explicitly interrelated figure as the stereotypical "LGBT" person by navigating the authoritarian interests of state and global hegemonies and the crisis of authority that arises from these experiences, collapsing a spectrum of queer desire restrictive ontologism that exclude many. Like other Asian countries Sri Lanka also criminalize same sex relations for colonial legacy and 
has not experienced a significant change in the incidence of its legal framework gender diverse people (Panditaratne, 2016). Sri Lanka and Bangladesh share same condition in case of recognizing the gender diverse people. There is no significant change seen in terms of acknowledging the diverse people in both counties. However, Sri Lanka has no official recognition of third gender for them outside conventional understandings of the culture; while local activists have been very outspoken and prominent in their battle to criminalize discrimination but like Bangladesh Sri Lanka also have penal provision to penalize homosexuality.

\subsection{Nepal}

On year 2007, in the Pant v. Nepal decision, the Supreme Court of Nepal ruled that the government should create a "third gender" category on official documents and government papers, including allowing people to identify themselves on official documents. It also argued that all legislation discriminated towards people on the basis of their sexual identity should be abolished and that equal rights should be extended to everyone regardless of their sexual orientation or gender identity (SOGI) (Oestreich, 2017). Hijras (generally transgender women) has a long historical background in Nepal and neighboring nations, claims that this background has affected a third gender decision by the judges. Nepal has never criminalized same-sex marriages and the designation of lesbian, homosexual, bisexual or transgender. Current draft defines sexual acts as occurring between a man and a woman (penile-vaginal sex) Unnatural sex is not defined in the Civil and Criminal Code (UNDP, USAID, 2014a). It should be made clear that unnatural sexual acts will not be interpreted to criminalize consensual adult same-sex activities and relationships. Nepal shows very progressive attitude to recognizing the gender diverse people in terms of Bangladesh by including the third gender in the census and voter rolls and by not criminalizing LGBTQI+ population.

\subsection{Afghanistan}

Homosexuality in Afghanistan is a controversial topic barely mentioned in the media and strongly condemned as unethical and un-Islamic. Since, sentence of homosexuality is a punishable offence with death sentence as per the newly developed Penal Code of Afghanistan, no figures exist thereby, to show the scale of the country's lesbian, gay, bisexual, and transgender (LGBT) population (Ahmadzai, 2016).

\subsection{Bhutan}

While conservative, Bhutanese culture was compassionate, welcoming, and open to everything. There is no connection to the world outside their own cultures, though, for most Bhutanese. Most do not know that there are LGBT people, and even those who do, always feel that in Bhutan they do not exist. While Bhutan has no overtly violent culture against homosexuals, a statute dating back to colonial times criminalizes the same sexual behavior. The Criminal Code states, if the defendant engages in sodomy or any other sexual activity which is contrary 
to the essence of the crime then it is punishable with a prison sentence of between one and 12 months. However, as "criminal intent" must be proven in order to be found guilty of this offence, there have been no reported convictions. There is no legal recognition of same sex couples; gay marriage does not exist in Bhutan (Tshering \& Wangdi, 2020). Yet views still tend to shift quickly. LGBT activists have set up Facebook pages with the proliferation of the internet and social media which serve as a public space for the LGBT community, and are also used to advocate for greater visibility. In June 2019, the lower house of Parliament voted to abolish two parts of the 2004 criminal code of the country, which made "unnatural sex" illegal between consenting adults. However, the bill must first be approved by the National Council, Parliament's upper chamber, before it is submitted for royal approval. Provisions like this one curtail lesbian, gay, bisexual, and transgender (LGBT) people's rights and freedoms, subjecting their private lives to unjustified scrutiny.

\subsection{Myanmar}

Prejudice against LGBT participants-lesbian, homosexual, bisexual and transgender-in Myanmar is deeply entrenched. It is commonly believed that their sexual orientation is the result of moral transgressions in a previous life and penal provision criminalized homosexuality. Therefore, actions to opt out as lesbian, homosexual, bisexual or transgender can be painful and can also lead to friends and family being rejected. Popular culture contributes to the stigmatization of Myanmar's LGBT people, and it is particularly detrimental to depict gay characters in films. The protagonists appear to show clownish behavior, in which their sexual nonconformity is made comically grotesque. That is normal for them to change their minds and become straight at the end of the movie, reinforcing the concept that being LGBT is essentially an option (Aung, 2019). Although Myanmar have conservative through about same sex relation but they also show tolerance about gender diverse people. The media ported LGBTQ+ community in negative manner. The same sex intimacy is punishable offence in Myanmar like Bangladesh. However, both states recognize third gender identity.

\subsection{Thailand}

Though Thailand has a reputation as one of the most tolerant countries in Asia towards LGBT individuals, legal recognition and protections remain far from liberal. Many legislators and legal practitioners come from conservative backgrounds, and believe in the traditional heterosexual family structure and gender roles. Administrative policies and legal reforms during the recent history of Thai law bear roots from those of the nineteenth and twentieth centuries within the Thai legal system to promote and protect civil rights, freedom, and liberty by the enactment of a new constitution in 1997. An impudence cited in these changes was international: Thailand is playing a greater role in a globalized community and economy and thus needs to harmonize laws with more liberal countries 
(UNDP, USAID, 2014b). Extremist language has been aimed at LGBTQ+ in Bangladesh but Thailand show very positive attitude about their LGBTQ+ community. However, they do not develop any legal framework for same sex marriage.

\subsection{Philippines}

There really is no law in legal documents to fix the process of changing one's sex. In part, the courts have dealt with the rights of intersex people to choose their sex and to correct legal records. Although the Philippines have a historical context on gender diversity at the state level, there are pro- and anti-LGBTQ+ policies from various ministries, agencies and private organizations. Good laws include anti-discrimination ordinances and racial harassment and the code of ethics which foster respect for diversity and foster well-being of LGBT people. The negative policy applies to the discharge of cross-dressers from the military on the grounds of sexual identity and the banning of entry into bars and clubs (UNDP, USAID, 2014c). In Philippines, family relationships are regulated by the Philippines Family Code, which came into force in 1987, and the Code explicitly specifies that marriage is between a man and a woman. In Philippines there is no legal recognition about the same sex marriage as Bangladesh. However, Philippines show tolerated attitude about the LGBTQ+ community and they do not acknowledge third gender identity likewise Bangladesh.

\subsection{Vietnam}

Homosexual acts and transsexual identity have been documented in the history of Vietnam, much as in other countries around the world. The Vietnamese culture had no clear bias or differentiation before modernity. Non-normative sexual preferences and gender identities are traditionally seen and debated as male homosexuality, as a patriarchal and patrilineal culture, males and females are seen as serious and evident manifestations of homosexuality. The Legislation on Marriage and Family first addressed individuals of different gender identities, gender expression and the rest of society with same-sex relationships in 2000, when the law was revised to include a ban on same-sex cohabitation and marriage. State media deemed homosexuality a "social evil" equivalent to gambling, prostitution and drug trafficking in 2002, and called for homosexual couples to be arrested. Later decrees made illegal same-sex adoption and surrogacy as well as marriages carried out abroad and to aliens of the same sex in 2002, 2003 and 2006. Following these decrees, police searches of LGBT-friendly institutions became widespread and the LGBT community was forced further underground. In Viet Nam, the LGBT community has grown stronger over the years, overcoming challenges. NGOs and other media are working to resolve Vietnam's LGBTQ+ problem (UNDP, USAID, 2014d). Having a strong historical background unlike Bangladesh the gender diverse people in Vietnam faces much discrimination in various aspects. Both the states acknowledge third gender identity but criticize 
the same sex intimacy.

\subsection{Subsisting Legal Mechanism in Asian Countries}

Table 3 below depicts the legal mechanism scenario amongst various Asian countries.

\section{Problem Statement}

Bangladesh as a nation does not recognize the gender diverse population except the conventional two genders and denies the existence of other gender identities since time immemorial. Throughout recent years after many considerations, the nation recognized "Hijras", who are a cultural faction rather than a gender identity as "Third Gender". This term has no proper definition nor does clarify the gender identities of people belonging to the third gender. This creates complications in a multitude level primarily regarding the property, inheritance and adoption rights of the "Third Gender" population and secondarily creates rather grave complications regarding the basic rights for other gender identities who are yet to be recognized. This research intends to investigate the existence of different gender identities beyond the conventional two genders and the third gender in Bangladesh and aims to coin the terminologies the different existing gender identities. Furthermore, the research explores the barriers and expects to make a thorough analysis in order to look for solutions in relation to the recognition of the existing gender diverse population.

\section{Research Methodology}

To make the research paper acceptable and persuasive, the researchers used mixed research techniques, conducting both qualitative and quantitative research

Table 3. Summary of Legal Mechanisms against Gender-diverse population in Asia.

\begin{tabular}{|c|c|c|c|}
\hline Country name & Homosexual activity & Same-sex marriage & Penal Provision \\
\hline Afghanistan & Illegal (death penalty as punishment) Since 1976 & Not Legal Since 1971 & Yes \\
\hline Bangladesh & Illegal (imprisonment as punishment) Since 1860 & Not legal Since 1860 & Yes \\
\hline Bhutan & Illegal (imprisonment as punishment) Since 2004 & Not legal Since 2004 & Yes \\
\hline Myanmar & Illegal (imprisonment as punishment)Since 1886 & Unrecognized Since 1886 & Yes \\
\hline Nepal & Legal Since 2007 & Ambiguous & No \\
\hline Sri Lanka & Illegal (imprisonment as punishment)Since 1885 & Not legal Since 1885 & Yes \\
\hline Thailand & Legal Since 1956 & Unrecognized Since 1932 & No \\
\hline Pakistan & Illegal (imprisonment as punishment)Since 1860 & Unregistered cohabitation Since 1958 & Yes \\
\hline Philippines & Legal Since 1900 & Not legal Since 1988 & No \\
\hline Viet Nam & Legal Since 1992 & Unrecognized Since 2013 & No \\
\hline
\end{tabular}


Data collected and analyzed for this research should be considered as accurate, reliable and authentic. These methods were necessary for collection of substantive data and relevant information for the research paper. The primary research method for this study was literature review and desk review. While Literature research focused on acquiring theoretical knowledge about a concept or topic, Desk research helped the researchers to gather facts and existing research data that helped to answer the research questions. Through literature review, the researchers surveyed scholarly articles, books, and other sources relevant to the field of research. Since the literature review acknowledged the work of previous researchers, and thus, assured the researchers that the work had been well conceived. Desk research was basically involved in collecting data from existing resources. For conducting Online Desk Research, the researchers found incredible amount of data available online. Government published data related to social, financial and economic aspects were accessed online. Comparative analysis of the existing bills, legislations etc. that had been for ensuring rights of the gender minorities was conducted.

The researchers performed secondary research through conduction of surveys and interviews with proper sampling and maintaining proper research monograph tactics following the "discussion method" of qualitative approach to research. The researchers conducted a survey through an interactive questionnaire, on online platform and via street or door-to-door interviews and three hundred responses from various age groups, ranging from 13 to 55 were gained. Furthermore, detailed in-depth interviews and focused group discussions of primary beneficiaries and secondary stakeholders were conducted and held accordingly on online platforms via Zoom, Google Meet, and WhatsApp. Thirty people from different gender identities were interviewed and their identities have been kept anonymous with dedication. The researchers portrayed their thoughts and their expectations from the society in the paper. The secondary stakeholders helped the researchers to understand about society's viewpoint regarding people from different gender identities. Interview sessions with representatives from various religious groups, the Government, law enforcement agencies, media persons, policy makers, lawyers, activists etc. were conducted on online platforms via Zoom, Google Meet, and WhatsApp. Finally, once the desk and literature reviews, constraint classification and modeling techniques were identified, a conceptual framework for total research management was outlined. The researchers then focused on drafting an apt research paper that would be the voice of different gender identities. This study was conducted in between January 2020 to September 2020.

\section{Findings}

Based on the online survey, street/door-to-door interviews and surveys, and in-depth interviews and focused group discussions with the primary beneficia- 
ries and secondary stakeholders, the researchers have accumulated substantive data to deduce results and suggest recommendations.

\subsection{Research Questions}

- What are the major legal barriers while coining the terminologies of different sexual minorities and acknowledging gender identities existing in the context of Bangladesh?

- Should there be separate legislation addressing the terminologies of existing sexual minorities and people of all gender identities in Bangladesh?

- How can we define terminologies addressing Gender Diverse Population through acknowledgement of Gender Identities?

- What could be the best possible recommendations for ensuring rights in respect of all gender identities?

\subsection{Results from Online Survey and Door to Door Survey}

The researchers have conducted an online survey and door to door surveys where 300 people voluntarily filled out the detailed online survey throughout Bangladesh comprising sets of questions from different horizons. Furthermore, with an intention to reach the mass people, the researchers conducted the same survey, reaching door to door in Dhaka. However, although the researchers reached out to 50 people, 30 people took part in the survey. With most interviewees belonging in the age group of $19-25$, they represented the voice of the future Bangladesh, and they were mostly representing the urban Bangladesh. One interesting aspect of this surveying was that, major portion of the interviewees were females or women.

\subsubsection{Level of Tolerance for Different Gender Identities in the Community} Figure 1 and Figure 2 show the age and gender demography of the surveyed

\begin{tabular}{|c|c|c|c|c|}
\hline \multicolumn{5}{|c|}{$\begin{array}{l}\text { In which range, is your age? } \\
\text { In which range, is your age? }\end{array}$} \\
\hline 10.33 & 70.57 & 12.14 & 5.51 & 1.45 \\
\hline $13-18$ & $19-25$ & $26-35$ & $36-54$ & 55 and above \\
\hline
\end{tabular}

Figure 1. Age range.

\begin{tabular}{|ccc|}
\hline & Your Gender \\
& Your Gender & \\
& $57.65 \%$ & \\
$37.84 \%$ & & $4.51 \%$ \\
\hline Male & Female & Others \\
\hline
\end{tabular}

Figure 2. Gender. 
participants. Upon asking whether all human beings were born free and were to be considered equal in rights or dignity or not, Figure 3 shows that, while a major portion of the survey interviewees believed in equality in terms of rights and freedom, three percent were unsure of such access to equal dignity, and the remaining five percent of them seemed to have disbeliefs about all human beings born free, without any restriction or limitation in terms of enjoying rights and freedom.

Furthermore, the interviewees were asked what was the most important attribute for a person to survive in the society as depicted in Figure 4 with respect and dignity, it was evident that morals and ideologies that a person holds were very much appreciated and thought about. Next came about the importance of the character and the attitude that a person withholds. The survey results showed that a person's gender was not to be given much importance when the topic of discussion is about his or her attributes.

The reason the two former questions were asked was to determine whether people actually be willing to accept that people from different gender identities and sexual orientations are fellow human beings too, with the same need for basic human rights just like others. Although sixty-three percent of the survey attendees answered that they believed in the freedom of people from all gender

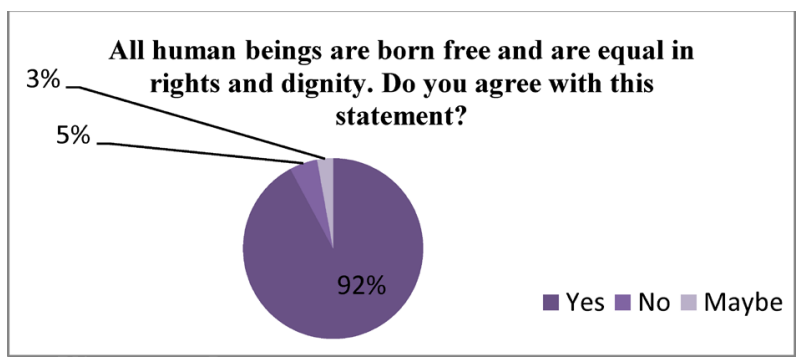

Figure 3. Opinion about equal rights and dignity.

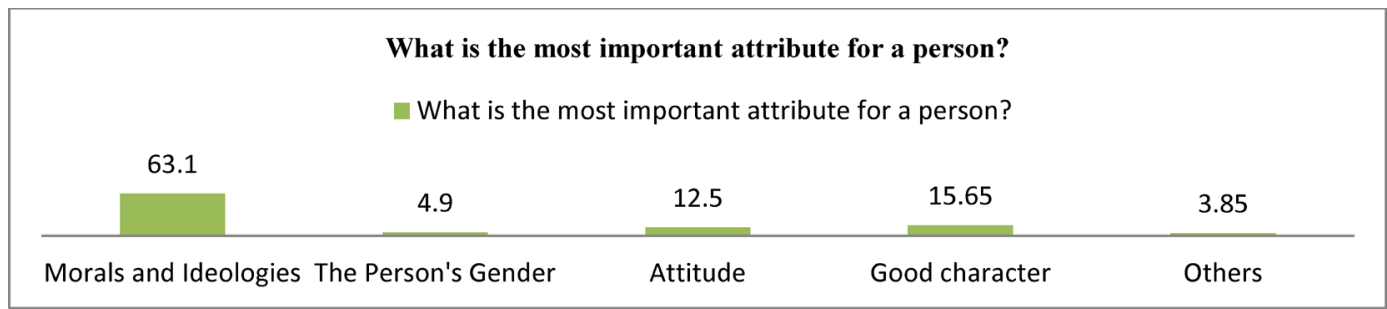

Figure 4. Most important attribute for a person.

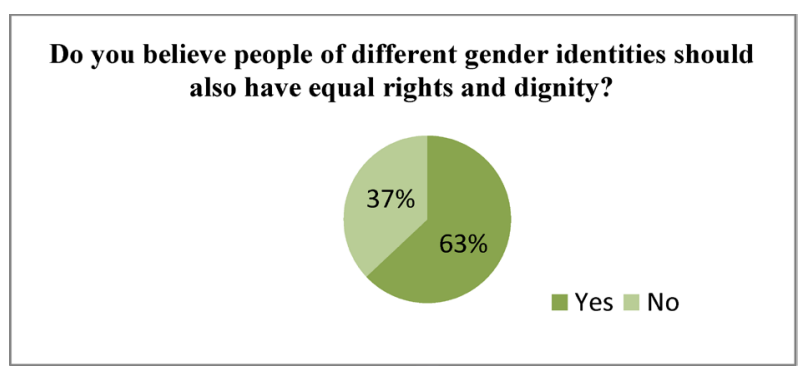

Figure 5. Opinion about equal rights and dignity. 
identities, some of them were skeptical about their own beliefs. Furthermore, real life scenarios depict a different picture, where people from other gender identities apart from males or females are often discriminated and suppressed in the Bangladeshi societies.

\subsubsection{Possibility of Coining the Gender Terminologies for Different Gender Identities}

Among 330 participants, although forty-one percent claimed to understand the term LGBTQI+, according to Figure 6 a majority portion could not state the names of the terms of the abbreviation. It is to be mentioned that Bangladeshi society often confuse Intersex with Transgender, due to lack of opportunities and outlets for gaining knowledge about existence of different types of gender identities and sexual orientations.

As shown in Figure 7, majority of the interviewees were skeptical about whether they would be able to publicly come out or not. Although some interviewees were confident and aware about the rights that they deserved to enjoy and preferred to be identified as their distinct identities apart from males and females in the society before all however the number is quite low.

Since, people from different gender identities and sexual orientations exist apart from males and females, and since they cannot come out publicly due to lack of legal recognition, in the current scenario, lawmakers need to coin different gender terminologies in order to give the country's people proper recognition. The path to achieving such a legislation where different terminologies would be defined would be a long one, which would require several reformations, social acceptance, amendments of necessary laws, discussions etc.

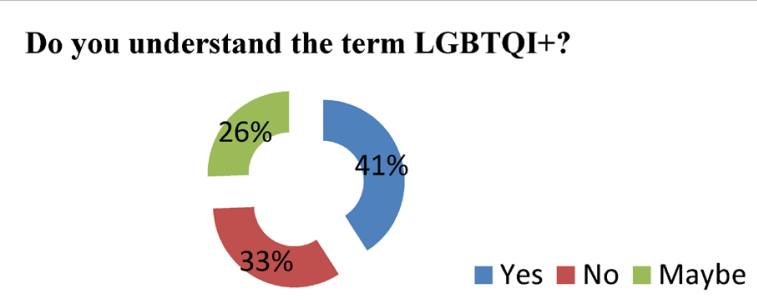

Figure 6. Understanding of the term.

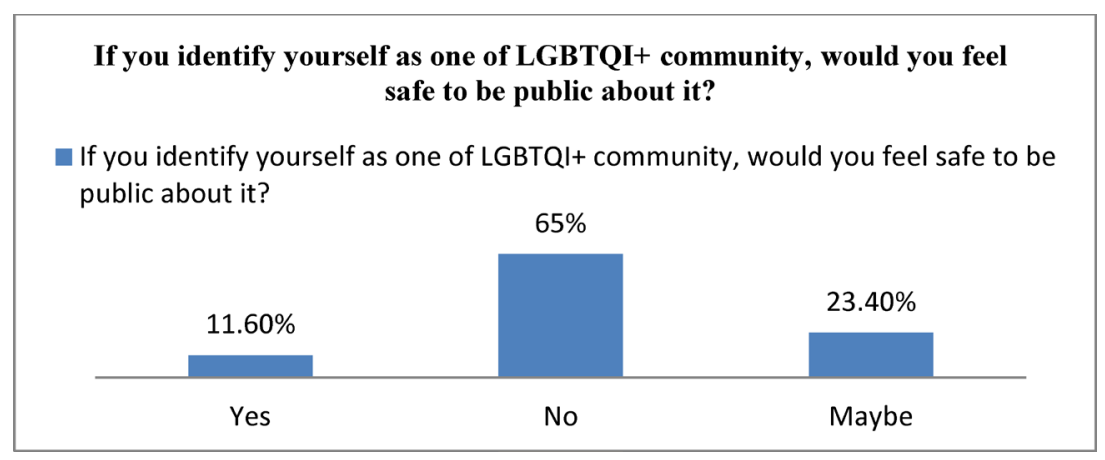

Figure 7. Indentifying as a gender diverse population. 


\subsubsection{Existing Stigma towards the People of Different Gender Identities}

Upon asking whether people who were from different gender identities and sexual orientations were suffering from sickness or not, as shown in Figure 816 percent of the participants considered it a sickness, 21 percent attendees were confused and majority opined that having other gender identity is not a sickness, it may be a condition, but only because it is something so rare that people find it difficult to normalize it.. A sickness can be cured by treatment, but since it is a feeling, coming deep down from a person's mind, or it happens because of hormonal imbalance and innate birth complexities, one cannot change that, and one should not, because it is not harming anyone. Several attendees believed that a day would come when the concept and society's reaction to "third gender" and other gender identities would be normalized. Some participants pinpointed the fact that due to lack of knowledge and understanding, the society has wrong notions about the existence of people from different gender identities. Because of religious restrictions and societal prejudices, it becomes difficult for the society to accept people from cis/trans, binary/non-binary groups as normal human beings. Furthermore, gender spectrum is so sensitive that, even in modernized societies like of the United States of America or of Switzerland, rights of the gender diverse population have not been yet recognized, and they are often termed as not normal, hence it is of no surprise that in Bangladesh, a country which is filled with superstitions and prejudices, many people consider being gay, lesbian, transgender etc. as a sickness. A ray of hope certainly arises when the participants gave their engaging responses on how considering people from different gender identities to be sick and not normal was wrong, and they further presented their perceptions on why it should be established that belonging from gender identities other than males or females is dignified as well.

In Bangladesh, social bonding and family bonding are given utmost importance. Even though, family members are supposed to be a person's greatest supporters and guides, the scenario in real-life is not so trouble-free. Due to difference in ideologies, thoughts and age and generation gaps etc., a person often seems to have distinct thoughts that contradict with his dear family members. And, in Bangladesh, conversations related to gender studies and sexual orientation studies are not so common because of existing orthodox mentality. Thus, when every participant was asked about their hypothetical opinions on whether they would be coming out to their families and whether their families would

Do you consider it a sickness if people are of different gender identities other than male or female?

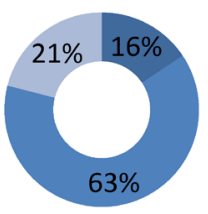

- Yes $\square$ No $\square$ Maybe

Figure 8. Stigma towards gender identities. 
support their choices of other gender identities other than males or females, it was not a nonplussed fact they people would be unwilling to come out to their families knowing that their families would not support their decisions. However, a ray of hope certainly has arisen when a portion of the interviewees showed that their progressive families would possibly support their beliefs.

\subsubsection{Possibility of Social Acceptance of Different Gender Identities in Bangladesh}

Bangladeshi society is not very welcoming towards people from the gender diverse population. Since people from the transgender, intersex, third gender groups have often been tortured and harassed and MSM/WSM have been criminalized as well, it is obvious that people would feel scared of expressing themselves freely and that fear is also expressed by the attendees as shown in Figure 9 and Figure 10.

Bangladesh is one of the most populous countries of the world, where except for the "Hijra" community, people from other gender identities apart from males or females have to stay closeted as they have fear of losing their rights to lives. Despite of the scenario, often people from the gender diverse population express their true-selves amongst their trusted ones. Thus, as per Figure 11, around 155 participants claimed to know members from the LGBTQI+ community in Bangladesh.

The researchers wanted to know whether the survey attendees would acknowledge the existence of the gender diverse population of the country and whether would accept them absolutely as they are or not, thereby ensuring that

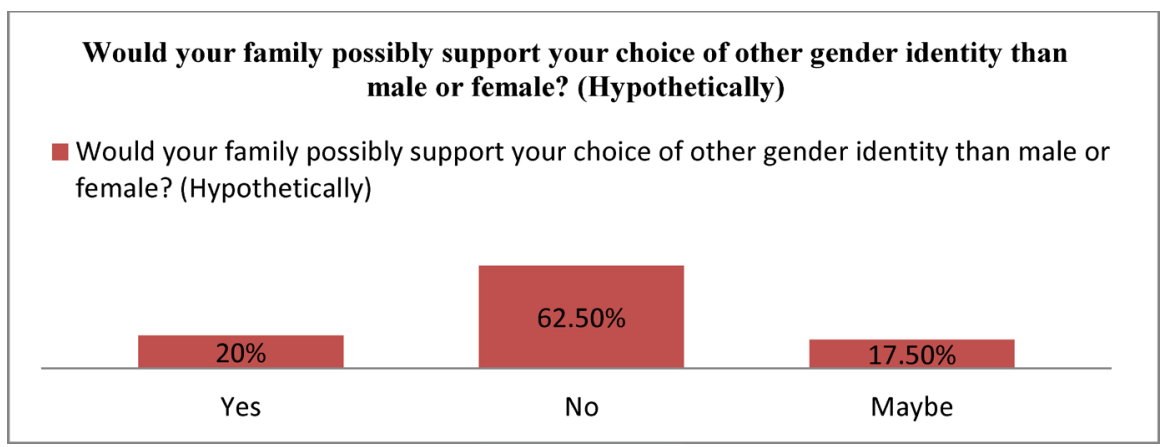

Figure 9. Acceptance in family.

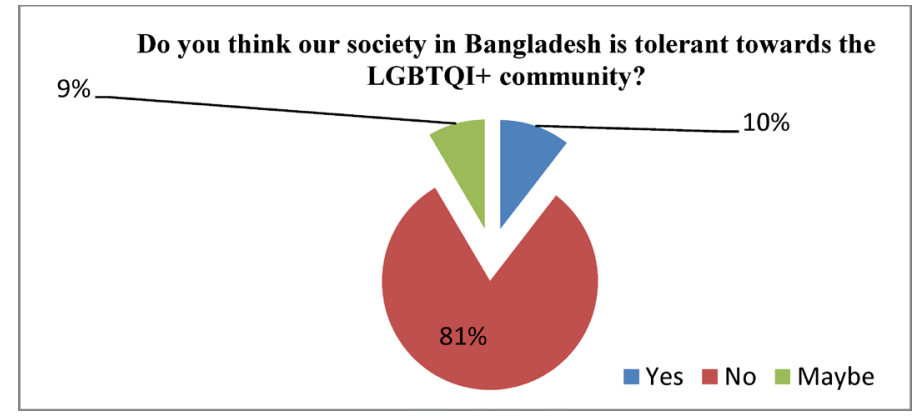

Figure 10. Tolerance in Bangladesh. 
society regards their existence and state and its people give them equal treatment and accesses, and the survey results were quite satisfactory as seen in Figure 12 . But whether these people would actually, in real life scenarios, behave properly and accept people from the LGBTQI+ truly or not is a matter of great concern.

\subsubsection{Possibility of Separate Legislations and Policies}

Based on survey results it seems that people of Bangladesh are progressing ahead and are quite ready to accept the existence of LGBTQI+ community in Bangladesh, however, the real picture depicts a different scenario. Hence, when asked whether the state should be tolerant to different gender identities and acknowledge their existence, as depicted in Figure 13, even though a major portion of the attendees believed that the state should do so, they were perplexed about whether the state would actually do it or not and how would that acceptance be agreed to be acknowledged upon, considering Government would be unwilling to displease more than half of the population.

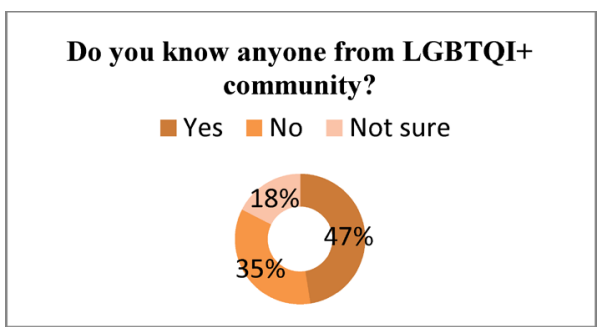

Figure 11. Knowledge of the community.

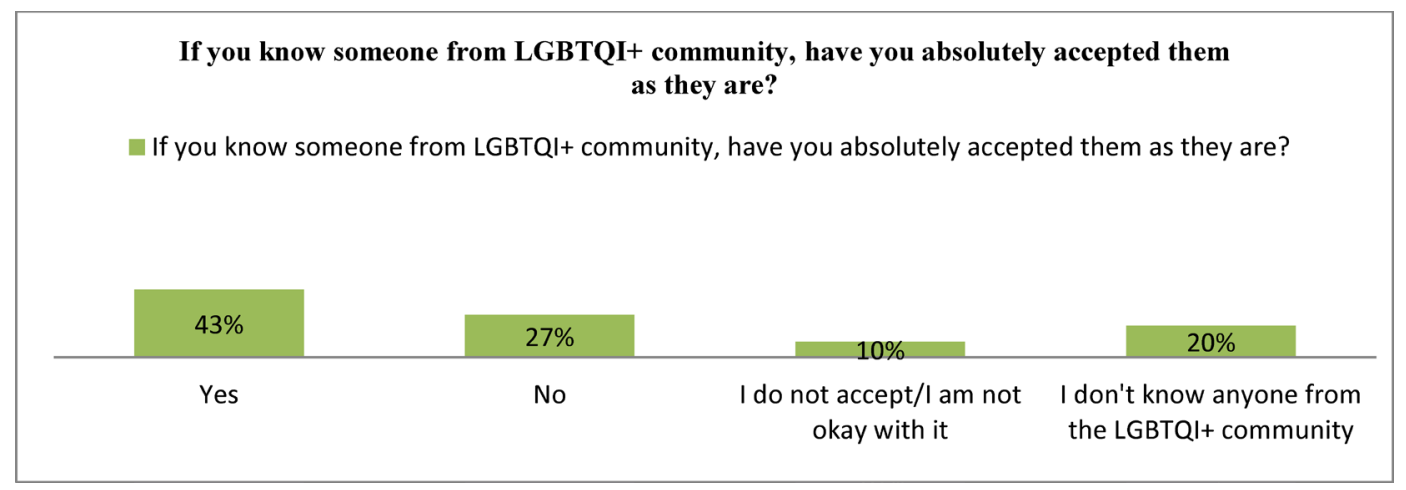

Figure 12. Acceptance of individuals of the community.

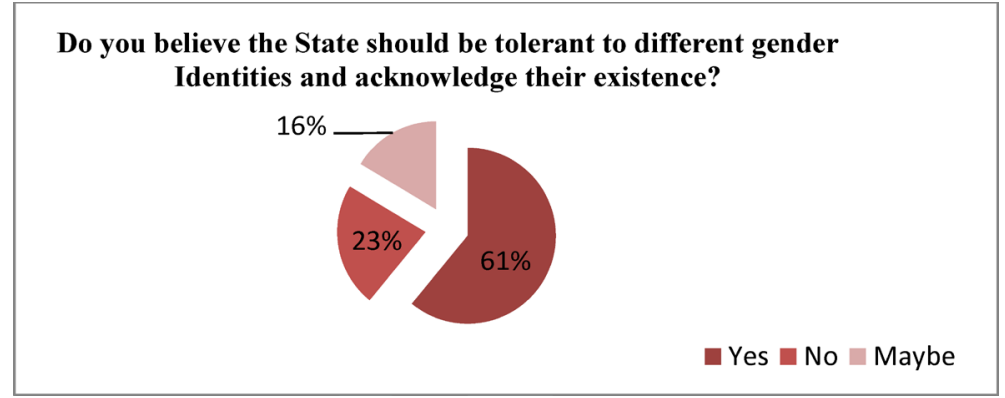

Figure 13. Tolerance of the state. 
The people from Gender Diverse Population should have rights related to inheritance. Over the years, there have been thousands of cases piled in courts, where transgender groups and intersex groups were seen to be deprived of their rights to ancestral properties only because of their different gender identities, and they often cannot buy or sell properties, because many sellers and buyers would not prefer to do contracts with them because of the complexities. In addition, there often arises a question, so as to whether a person should receive inheritance related rights based on their current gender, or gender by birth. As per Figure 14, many believe that they should. A person, who via operation and surgery, changed his or her gender, sometimes claim to receive inheritance based on their gender during birth. In order to avoid all such complexities, a separate legislation should exist to save the GDP from such troubles and complex procedures.

Under Section-377 of the Penal Code of Bangladesh, person from the same gender if found to have physical relations would be penalized, thus implying that Bangladesh is against the existence of gays, lesbians etc. Again, under Section-390 of the Penal Code, marriages of same-sex people are considered to be public nuisance. Now, only because a person belongs from a different gender identity with a different sexual orientation should have penalized and punished law. Laws of Bangladesh, in compliance with Articles-19 and 27 which promise about equal opportunities for all citizens and equality before the law for all citizens respectively should be modified and updated in order to ensure that the people from the Gender Diverse Population are not being subject to wrongful arrests, violence and torture and discrimination, and majority of our attendees agree to that statement as shown in Figure 15.

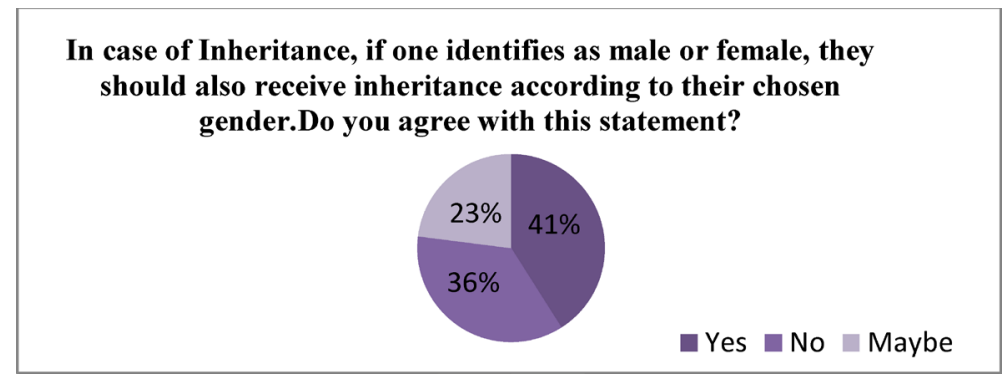

Figure 14. Inheritance question.

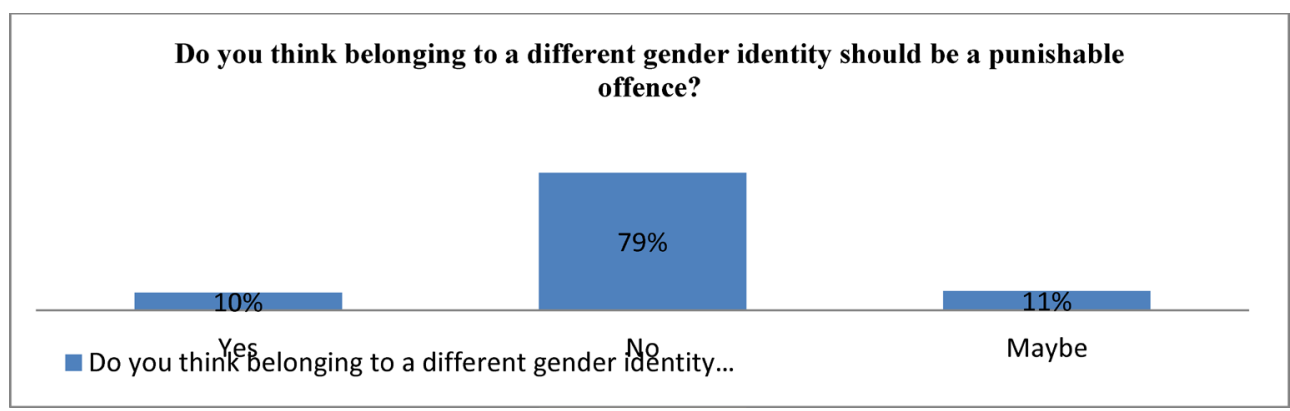

Figure 15. Determination as a punishable offence. 
People, irrespective of their age, class, social groups, caste, religion, gender etc. have the right to education. Education is one of the basic necessities of life. In order for every resident and citizen of the state to receive this fundamental right to education, governments and policy makers should make necessary arrangements for creating an environment, which would be safe and secured for every attendee, including the people from the Gender Diverse Population of the country. People from the GDP are often bullied and discriminated and harassed. Although there are talks about establishing distinct educational institutions for the GDP. However, in order to promote inclusivity and solidarity majority of the attendees believe that, irrespective of their gender identities everyone should receive education together as shown in Figure 16.

Media can play a great role in stimulating conversations about the GDP and LGBTQI+ community of the country. However, often in Bangladesh, media portrays the characters of LGBTQI+ community in a negative way, often mocking or bullying them because such programs are often well-received by the audience. However out attendees express that they are more comfortable with the positive representation of GDP as shown in the global media as shown in Figure 17. Based on how well media portrays the LGBTQ community, policy makers can be influenced through several media contents to talk more about the rights of the Gender Diverse Population in open environments and public places. Thus it is important for media to be active participators in elevating the rights of this population.

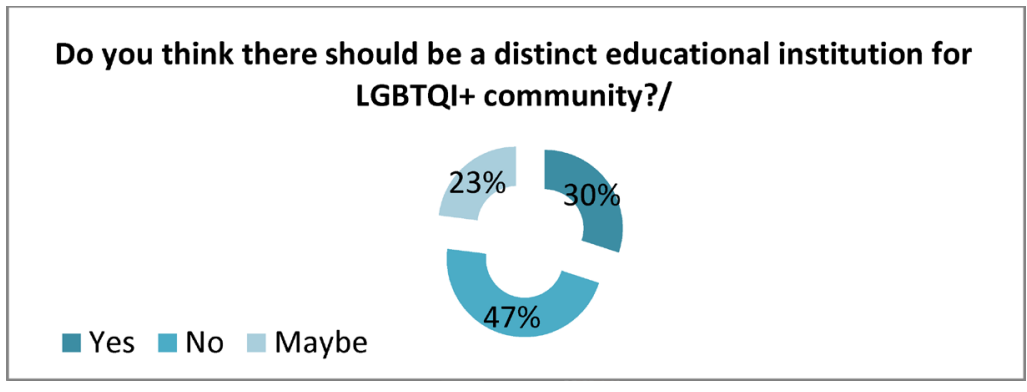

Figure 16. Educational institute.

If you have seen any global media representation, for example-movies etc. regarding LGBTQI+, How did you feel about it?

I think it is normal and I am comfortable watching it

I do not think it is normal and I was uncomfortable watching it

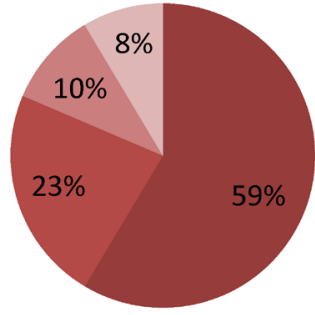

Figure 17. Media representation. 


\subsection{Results from In-Depth Interviews}

Findings from the in-depth interview sessions and door to door interviews show a contrasting picture from what has been painted from the online survey, which makes an interesting case and shows the dichotomy of the survey and highlights the polarity between urban and the rural context of Bangladesh. As it has have already explained that most of the participants from the online survey were from a well-off, educated and substantial background. This phenomenon heavily affects their thinking, way of life and opinions. Whereas the in-depth interview focuses on people from the root level and door to door interviews gives us the representation of the general public. These data contrast represents a cohesive idea about the overall picture regarding the existence of different gender identities and the necessity for coining the terminologies in order to eliminate the problems faced by this community on a daily basis and the further discussion explains the reasoning.

\subsubsection{Major Legal Barriers While Coining the Gender Terminologies}

From the conversations with the stakeholders and other secondary groups, the researchers have concluded that there are some major barriers that serve as an impediment in coining the terminologies and acknowledging the legal status of different gender identities.

1) Ignorance in Terms of the Existence of Different Gender Terminologies

Ignorance is one of the geneses for the coining of the different gender terminologies and all of the primary stakeholders agreed to this unreservedly. First of all, there is no representation of different genders except male, female and "third gender" in any governmental paperwork. The sphere of third gender only includes the Transgender population. This inclusion is also very recent when Bangladesh denied of having any gender identities other than male, female and transgender which is called third gender per se. No representation from any other gender is found in the civil lives lead by the citizens whereas the research shows clearly that many other gender identities do exist in Bangladesh other than the three mentioned above. With no representation in official papers and other sphere Put differently, it was a template for national welfare-ism of public life, ignorance keeps stemming and reduce the chance of recognition of the other gender identities creating a situation of alienation, discrimination, and otherization. This, as a result, creates an environment where the people who identify themselves as different genders are afraid to disclose their identity. Even if they do so, they are to live with constant fear of discrimination, violence and discomfort. Since the identities of this community are surrounded by incertitude their legal rights like inheritance among other civil rights face impediment.

No mention of the different gender identities in any textbook or curriculum speaks volumes about the incomprehension about this particular issue being isolated. No awareness means that no conversation regarding these different gender identities are taking place. Consequentially there is no development of 
sensibility among the people which operates as a stimulant in inciting discrimination and intolerance.

\section{2) Misconception of Existing Gender Identities in Bangladesh}

The first misconception in regard to the gender identity is the fact that most of the citizens in Bangladesh are aware of the existence of Transgender population who are more often referred to as "third gender". However, the existence of other gender identities is not acknowledged. There are multiple reasons behind the denial which will be discussed later. The only reason for acknowledging Transgender is because of the "Hijra" culture in Bangladesh. This particular culture shows the negated situation in which the transgender people live segregated from a life without their basic civil and political rights. Their visible struggle for the longest of time has pushed the authorities to finally recognize them and give them some kind of aid and rights. Some of the Transgender cases shared with us that recently they have heard about policies for helping them integrate into the society. Some transgender representation has been introduced in the politics as of late and thus some actions are being taken although very minimal but those actions have not been implemented yet. Nonetheless, the Transgender cases disclosed that among their Hijra community there are people of other gender identities than Transgender. So, banding all of them as the Third gender of Hijra is problematic because there are Inter-sex, Gay and other gender identities in the mix. While going through the interview process many of the secondary stakeholders were unaware of such inclusion of different gender identities and some were confused about the differences between different identities. The lawyer from Feni was only aware of Inter-sex gender identity other than Transgender and believed them to be "unnatural". This label of unnatural stems from the legal language that is used in the Penal Code, 1860 section 377 which uses the word "unnatural offences" in order to criminalize sexual actions of other gender identities. This particular section incites violence and discrimination but what is misunderstood about this section is that it criminalizes the sexual actions between same sexes but it does not criminalize other gender identities themselves. So, in the opinion of the cases, they believe that this section is used as a tool to threaten their right to life and to instigate violence and savagery. The human rights activists also see this particular section as a tool kit for violence, since there is no other method to persecute people from different gender identities.

3) Socio-religious and Cultural Uneasiness towards Different Gender Identities

From the conversations with the primary stakeholders, one of the most evident barriers in terms of not recognizing different gender identities is deeply embedded socio-religious and cultural uneasiness. Taking the context of Bangladesh the society is heavily influenced by the religious values of the people and when talking to the religious leaders the reason as to why there has not been any sensibility developed in the past years regarding the question of different gender identities can be evident. Firstly, in every religion prevalent in the country the 
opinion regarding different gender identities other than male and female are critical. To start of the Islamic perspective does not agree with the idea of other genders which a human is not born with and in the process heavily and directly condemns sodomy. Since most of the population conform to Islam as their way of life. The ideology and criticality of different gender identities impact the mindset of the Muslim population and as a consequence most of this demographic are reluctant to accept different gender identities. However, sometimes distorted ideology of Islam is also used by individuals to incite violence and hate towards people of different gender identities which are not supported by the religious leaders and the time and again stressed on the fact that Islam does not approve of the violence but neither does it approve of other gender identities. In terms of the second widespread religion in the country which is Hinduism, various scripture does have representation of different gender identity but the followers at the end of the day view these identities as unnatural and do not conform nor celebrate other identities than male or female. Furthermore, in Christian scriptures the ideas of different gender ideology is not clearly condemned but it boils down to the cultural infrastructure of the society. From the interviews conducted and the street responses, it is evident that even people from different gender identities feel uncomfortable to talk about their identities in the context of religion because of the contrasting view that it emits. However, more eminently the problematic disposition also lies in the cultural context. According to most of the cases of the research the individuals from this culture label different gender identities as a western borrowed culture. It is one of the reasons why acceptance is low and the discrimination keeps persisting. Since the culture and religion influence the thinking and policy of the society as a whole and shape the thoughts and ideal of the all the stakeholders involved the level of tolerance keep dropping and it is one of the major barriers on the road of achieving acknowledgement of different gender identities. This is one of the factors which shape public opinion and in a democratic society; the weight of public opinion is overwhelmingly cumbersome. Furthermore, the political parties push this agenda to ensure their vote banks are secured and when in power they do not support the other gender identities since the majority is against such gender ideologies. So, rather protecting the people from gender diverse population the government actually uses the law to repress or persecute them. Persecuting them would ensure their grip of power to some extent. Some religious extremist group also uses this narrative in their favor to spread hatred, incite violence and create chaos. This does not favor anybody but just their idea lifestyle and they push it to the extent that creates chaos in some circumstances. As long as the public opinion does not sway to the side of different gender identities and accept their choice to lead their life as they please and as long as the public does not develop a sensibility of tolerance towards the different gender identities the road to acknowledgement seems like a rough journey. 


\subsubsection{Separate Legislation for Different Gender Identities}

Majority of the cases including primary and secondary stakeholders agreed to the fact that there should be separate legislation if possible to safeguard different civil and political rights of the different gender identity population. Their opinions regarding this statement had various underlying reasoning. First of all there was a consensus between them that no matter what their gender identity is their right to life and property shall be protected as given under the constitution. Since disclosing one's gender identity can lead to endangerment o their life there must be some legal implication and reflections in the legislation to safeguard their life. Secondly, over the years various issues have been raised in terms of the property or inheritance rights of the people of different gender identity. In Bangladesh inheritance or property rights are governed under the religious personal laws of the individuals. Which means that an individual's property rights or inheritance rights will be given as per the religion that person adheres to. So, the disparity is created because the religious personal laws determine the proportion of the properties as per the gender and the relation of the receiver of the property with the deceased. Since the religious doctrines only recognize two genders it becomes a problematic situation for the people of other gender identities who do not conform to the conventional gender norms. So ambiguity remains whether they are entitled to any property at all. Even if they are how to claim that property or what portion of the property should be claimed. Therefore, to resolve these ambiguities according to the primary and secondary stakeholders there must be a separate legislation addressing this ambivalence in regard to the property rights and specific proportion shall be addressed as per the gender one identifies at. Other than the property rights people from different gender identities also face problems in regard to laws of adoption or guardianship. These rights are also governed by the religious personal laws and for the corresponding reason, there should be again separate legislation addressing these issues to make sure that people of different identities are being able to take note of their property and other civil rights.

\subsection{Protection of Rights and Liberty for the Gender Diverse Population}

A change cannot be brought in a day, it would require months and years, and tolerance and research and relevant laws and policies in order to bring in a systematic change in the society. In order Bangladesh to acknowledge the existence of people from all gender identities and sexual orientations, Bangladesh should first work on to improve the current status quo of the Hijra community or the "Third Gender". Based on interviews, survey, literature review, in Bangladesh, transgender and intersex people often are being subjected to uncalled for medical treatment with purposes of sterilization and surgery resulting in physical and psychological sufferings. And often, such bizarre and onerous preconditions were put before the victims could get legal recognition and protection of their gender identity from the society. With Bangladesh acknowledging the ones apart 
from males and females as "Third Gender" people, there has arisen needs to protect the rights and safety of them from religious and societal pressure. Rules and policies are to be designed to avoid surgeries on intersex and transgender without their consent. Furthermore, the existing laws lacked to provide a scope for the "third gender" to be involved in marriage or relationships; thus, their rights of liberty were often snatched under the shield of Section-377 of the Penal Code of 1860. The said section requires amendments. Again, although sex-change surgery has been made legal in Bangladesh, there lies confusion about the status of their gender identity post-operation. Often, the people mistake them to be transgender. Furthermore, people undergoing sex-change operations are not given access to guardianship, adoption etc. Laws need to be added so as to determine how their property and maintenance would be figured and sorted out. Again, since, in the name of religion and social culture, extremists seem to take the law in hands by killing and attacking people from different gender identities and sexual orientations, laws need to create provisions to tackle such extremism and chaos, and this can be done prior to acknowledging their existence in the state. Since, the state has often been alarmed about spread of diseases via MSM, state would require to create suitable conditions through which they would be able to receive proper medical treatment. Bangladesh, with continued efforts and small, necessary steps, hold the position to actually protect right to life and liberty and free movement for people from all gender identities and sexual orientations.

\subsection{Recommendations for Ensuring Equal Rights for all Gender Identities}

Questions arise so as to when people from the gender diverse population would rightfully be able to live their lives with dignity. Several steps can be taken in order for the state and the people of the state to recognize the existence of different gender identities and thus give them access to enjoy civil liberty and human rights. From the survey, in-depth interviews and street interviews, the researchers have gathered some specific recommendations to ensure equal rights for the people of different gender identities. If implemented these recommendations may open up a road to the acknowledgement and corroborate the equality among all the gender identities existing in Bangladesh.

- Enacting separate legislation for defining the different gender terminologies or amendment to include different gender terminologies in the existing legislation.

- Enacting a separate legislation addressing the legal issues that personal law covers, such as inheritance, marriage, guardianship and adoption, thereby establishing extensive rights of the Gender Diverse Population apart from rights to liberty, living freely and freedom of expression.

- Increase of social tolerance and this can be done only if state carries out various programs and campaigns to aware its people about the existence of dif- 
ferent gender identities and how everyone has equal access to human rights and justice.

- Inclusion of information about different gender identities in the national curriculum to create tolerance and sensibility towards them.

- Decriminalization of different gender identities rather than the conventional existing gender identities to ensure the safety, security and right to life of the gender diverse population.

- Inclusion of options of other gender identities in the governmental official documents.

- Raising awareness in educational institutions, the youth and juvenile minds spend a major portion of their days in their schools, colleges, universities, madrashas etc., thus if the young minds are taught about how constitution and international covenants and treaties acknowledge the rights of every distinct individual, then, society will progress ahead.

- The role that print media and news agencies can play to shape the mindset of people is unimaginable, people are heavily reliant and dependable on what the press shows to them, and people nowadays learn more from visuals, thus movies, documentaries are being made to educate people on different social issues. Hence, in Bangladesh, media can truly play a great role to change the way of thinking of orthodox people.

- Creating awareness regarding the different gender identities existing in Bangladesh outside of the Hijra community.

- Drafting relevant laws and policies to thereby protect the rights of the Hijra community, or of the people of the third gender.

- Creating opportunities and means and mode of access for the "Third Gender".

- Enacting and designing laws to criminalize and penalize the ones who discriminate against the GDP.

\subsection{Additional Findings}

In Bangladesh, people often confuse with the two distinct groups: transgender and intersex. The third gender of Bangladesh who are "the Hijras" are in reality people from Intersex Group. However, due to lack of knowledge and laws, they consider themselves as parts of the transgender group. Into the bargain, because of existing societal preconceptions and stigmas, people from the Hijra community of the country considers it a blot to talk about their sexual preferences. Again, many MSM and WSW are hiding themselves, pretending to be from the Hijra community. The MSM or gays and WSW or lesbians remain underground, with no public representation. Furthermore, it is believed that with social acceptance, and mutual understanding and proper governance, the rights of the Gender Diverse Population can be established in the orthodox, religious societies of Bangladesh. From the discussions, the primary stakeholders voiced some concerns about various issues like the day to day harassment they face. Especially the people who do not dress like conventional gender norms or who look dif- 
ferent but one of the most striking contrasts regarding the health of MSM (men having sex with men) people. Some of them voiced that the government declared in the United Nations that there did not exist any other gender identities than third gender in Bangladesh. However, Bangladesh submitted reports in WHO about the health concerns of MSM. This kind of contradictory behavior is actually hindering the government from implementing policies to ensure the proper health of this population. Since seeking medical attention for their health deterioration might result in persecution so most of them refrain from doing routine checkups and are sometimes scared to seek help from doctors. Since there is no acknowledgement there is no implementation of policies to safeguard their health and that is a deep concern shared by a lot of the cases in this particular matter.

\section{Challenges}

While conducting this research, the researchers had to overcome several challenges. Firstly, there existed a lack of operational definitions and measurement of gender identities and sexual orientations in Bangladesh. Because of this, major portion of the population of Bangladesh remained in dark, being unaware of existence of different gender identities apart from males and females. Since matters and discussions related to homosexuality were heavily suppressed and prejudiced in Bangladesh, it became a great obstacle for the researchers to gather interviewees from the Target Group who would disclose about various aspects of their preferred gender identities and sexual orientations. The fear of coming out and identities getting revealed were heavily embedded in the minds of people since they had a fear of losing their rights to live and could have been jailed and prosecuted. Furthermore, another challenge that the researchers came across was to actually motivate those who were willing to appear for the interview but were reluctant on answering several questions. Finally, it became extremely difficult for the researchers to obtain and derive high-quality data from a relatively small population size. The fear of public appearances was so embedded in the minds of the people that the researchers had a limited number of reaches. Accumulating overall perception from people of all classes, social groups, age groups, gender identities remained a crucial challenge as the researchers mostly could reach out to the young, educated, conscious citizens of the country.

\section{Limitations}

The research that we pursued has had several limitations. The researchers had difficulties during data collection and analysis. Because of issues related to and with the Gender Diverse Population of Bangladesh and LGBTQI+ communities of Bangladesh being so prejudiced and not-talked about, the researchers had access to limited number of primary stakeholders, aka, the Target Groups. Thus, while performing the research monograph, it lacked sample and selection biases, implying that, during in-depth interviews, the interviewees were less in number. 
Furthermore, the attendees of the surveys carried out for this paper were mostly representatives of the urban young generation; thus, the older generation's perception about rights of the Gender Diverse Population of Bangladesh was not covered; and furthermore, the survey results were quite urban-centric. Again, because of existent COVID-19 pandemic, offline door to door or street interviews could not be operated for a long period, which created hindrance in assembling a bigger sample size for in-depth and street interviews and surveys. Moreover, lack of previous research studies on the Gender Diverse Population of Bangladesh, specifically the LGBTQI+ community limited us from conducting a very detailed desk-based research.

\section{Conclusion}

It is undeniably true that in a country like Bangladesh, overcoming religious prohibitions poses serious challenges in ensuring rights of the gender diverse population. However, as a state, the constitutional rights are to be reflected in its attitude towards the people of different gender identities. Gender roles are absolutely socially constructed, and it is not biological. What is considered as natural may also be a societal contribution and changes in the mindset of the people can be brought with clear understanding of the concepts of the gender diverse community. While it is difficult to give this community acceptance in a broader social setting, their rights to life, freedom of speech, protection, shelter, right to not be discriminated have to be ensured since they are above all human beings. The research has identified the core reasons from legal, religious and social perspective as to why no legal status is still being ensured for the gender diverse population. Some positive reflections have also been found that gives hope that Bangladesh may be progressing in including gender diverse people in different sectors. From the comparison report on Asian countries, Bangladesh may take up understanding on overcoming barriers or rethink to determine the state's position on the said community. The survey shows that the urban young generation is getting more aware about the rights of the LGBTQ+ and they believe in giving freedom of expression. However, they do know that path to reach that stage would be a difficult and challenging one. Furthermore, from the perspective of law and policy makers, the enactment of laws and policies safeguarding the gender diverse population is an agenda for future. In their perspective, our society is not yet ready to undergo such a big step towards the acknowledgment of the different gender identities. The State mostly suppresses discussions like this due to religious restrictions. But elaborating on the terminologies and legally defining those may make people take a step towards understanding the rights of this community that are still to be ensured. The social reaction of the population of Bangladesh is itself a great barrier for the State to implement laws and policies for the gender diverse population. The initial step could be to give the gender diverse population a proper recognition that is to concede their existence in the constitution and in relevant laws. A call for recognition of legal status of the 
gender diverse population is represented in the attempt to define the gender terminologies on the basis of social context in the country.

\section{Funding Note}

This Research Paper was written under the supervision of Bandhu Social Welfare Society and with the funding of USAID.

\section{Conflicts of Interest}

The authors declare no conflicts of interest regarding the publication of this paper.

\section{References}

Ahmadzai, A. (2016, October 7). Afghanistan LGBT Community Living Under Threat of Death. BBC Afghan. https://www.bbc.com/news/world-asia-36884732

Ahmed, T. N. (2018, April 5). Punishment for Homosexuality in Bangladesh. The Daily Observer.

Amundsen, I. (2018). The Ruins of Bangladesh's LGBT Community. East Asia Forum.

Ashoka Bangladesh (n.d.). Ashoka Fellow Hosne Ara Begum. https://www.ashoka.org/en-bd/fellow/hosne-ara-begum

Aung, W. Z. N. (2019). Myanmar's LGBT Community: Between Old Laws and Enduring Stigma. Frontier Myanmar.

https://www.frontiermyanmar.net/en/myanmars-lgbt-community-between-old-laws-a nd-enduring-stigma/

Bangkok Post Public Company Limited (2012). Bangladesh Film Tackles Past Culture of Underage Sex.

https://www.bangkokpost.com/world/317273/bangladesh-film-tackles-past-culture-ofunderage-sex

Baudh, S. (2013). 10. Decriminalization of Consensual Same-Sex Sexual Acts in the South Asian Commonwealth: Struggles in Contexts. In C. Lennox, \& M. Waites (Eds.), Human Rights, Sexual Orientation and Gender Identity in the Commonwealth (pp. 287-312). London: University of London Press.

https://www.jstor.org/stable/j.ctv512st2.14

BLAST and others v. Bangladesh and others 55 DLR (2003). 363.

Chatterjee, S. (2014). Problems Faced by LGBT People in the Mainstream Society: Some Recommendations. International Journal of Interdisciplinary and Multidisciplinary Studies, 1, 317-331.

https://www.ijims.com/uploads/cae8049d138e24ed7f5azppd_597.pdf

Hossain, A. (2019). Section 377, Same-Sex Sexualities and the Struggle for Sexual Rights in Bangladesh. Australian Journal of Asian Law, 20.

https://papers.ssrn.com/sol3/papers.cfm?abstract_id=3516500

HRC (2004). What Does the Bible Say about Homosexuality?

https://www.hrc.org/resources/what-does-the-bible-say-about-homosexuality

Human Rights Watch (2016, May 27). All Five Fingers Are Not the Same. https://www.hrw.org/report/2016/08/16/all-five-fingers-are-not-same/discrimination-g rounds-gender-identity-and-sexual

International Commission of Jurists (2020). Pakistan: Transgender Persons (Protection of 
Rights) Act, 2018.

https://www.icj.org/wp-content/uploads/2020/03/Pakistan-Transgender-Advocacy-An alysis-brief-2020-ENG.pdf

Khan, F. (2019). "Queer” Pakistan. In Global Encyclopedia of Lesbian, Gay, Bisexual, Transgender, and Queer (LGBTQ) History (pp. 1194-1197). Gale. https://www.researchgate.net/publication/331654125_Queer_Pakistan

Khan, S. (2001). Culture, Sexualities, and Identities. Journal of Homosexuality, 40, 99-115. https://doi.org/10.1300/J082v40n03_06

Khandokar, N. (2019, October 15). A Third Gender Person Wins Upazila Election in Jhenaidah. Dhaka Tribune.

https://www.dhakatribune.com/bangladesh/election/2019/10/15/a-third-gender-person -wins-upazila-election-in-jhenaidah

Labu, N. (2018, April 25). Two Years after Xulhaz-Tonoy Murder, Killers Still at Large. Dhaka Tribune.

https://www.dhakatribune.com/bangladesh/crime/2018/04/25/two-years-xulhaz-tonoy -murder-killers-still-large

Massad, J. (2002). Re-Orienting Desire: The Gay International and the Arab World. Public Culture, 14, 361-386.

https://www.researchgate.net/publication/31272947_Re-Orienting_Desire_The_Gay_I nternational_and_the_Arab_World https://doi.org/10.1215/08992363-14-2-361

Michael, S. (2018, September 6). Campaigners Celebrate as India Decriminalizes Homosexuality. The Guardian.

https://www.theguardian.com/world/2018/sep/06/indian-supreme-court-decriminalise s-homosexuality

Obergefell v. Hodges, 576 U.S. 644 (2015).

Oestreich, J. (2017). Sexual Orientation and Gender Identity in Nepal: Rights Promotion through UN Development Assistance. Journal of Human Rights, 17, 265-279. https://doi.org/10.1080/14754835.2017.1357028

Ogles, J. (2016, September 6). 19 LGBT Hindu Gods. Advocate. https://www.advocate.com/religion/2016/9/06/19-lgbt-hindu-gods\#article-content

Out Right Action International (2020). Pakistan. https://outrightinternational.org/region/pakistan

Panditaratne, D. (2016). Decriminalizing Same Sex Relations in Asia: Socio-Cultural Factors Impeding Legal Reforms. The American University Journal of International Law and Policy/Washington College of Law, 31, 171.

https://www.researchgate.net/publication/307978149_Decriminalizing_Same_Sex_Rela tions_in_Asia_Socio-Cultural_Factors_Impeding_Legal_Reform

Reza, P. (2013). Lesbian Couple Arrested After Marrying in Secret in Bangladesh. Global Voices.

https://globalvoices.org/2013/07/26/lesbian-couple-arrested-after-marrying-in-secret-i n-bangladesh/

Robson, R. (2017). Educating the Next Generations of LGBTQ Attorneys. Journal of Legal Education, 66, 502-509. https://www.jstor.org/stable/26453499

Singh, P. (2015). Between Legal Recognition and Moral Policing: Mapping the Queer Subject in India. Journal of Homosexuality, 63, 416-425.

https://doi.org/10.1080/00918369.2016.1124700

Tharoor, I. (2016, May 3). These Bangladeshi Bloggers Were Murdered by Islamist EX- 
tremists. The Washington Post.

https://www.washingtonpost.com/news/worldviews/wp/2016/04/29/these-bangladeshibloggers-were-murdered-by-islamist-extremists-here-are-some-of-their-writings/

Tshering, U., \& Wangdi, S. (2020). Sexual Diversity in Bhutan. Bhutan Health Journal, 3, 24-27.

https://www.researchgate.net/publication/328651036_Sexual_Diversity_in_Bhutan

UNDP, USAID (2014a). Being LGBTQ in Asia: Nepal Country Report. USAID. https://www.usaid.gov/sites/default/files/documents/1861/Being_LGBT_in_Asia_Nepa 1_Country_Report.pdf

UNDP, USAID (2014b). Being LGBTQ in Asia: Thailand Country Report. UNDP. https://www.refworld.org/pdfid/54ed82784.pdf

UNDP, USAID (2014c). Being LGBT in Asia: The Philippines Country Report. https://www.undp.org/content/dam/philippines/docs/Governance/Philippines\%20Rep ort_Final.pdf

UNDP, USAID (2014d). Being LGBT in Asia: Viet Nam The Country Report. USAID. https://www.usaid.gov/documents/1861/being-lgbt-asia-vietnam-country-report

Wojcik, M. E. (2016). Sexual Orientation and Gender Identity Under International Law. Proceedings of the Annual Meeting, 110, 21-25. https://www.jstor.org/stable/10.2307/26420141

Yuhas, A. (2017, July 14). Supreme Court Legalises Gay Marriage across the US-As It Happened. The Guardian.

https://www.theguardian.com/law/live/2015/jun/26/supreme-court-rules-same-sex-ma $\underline{\text { rriage }}$ 